\title{
Editorial: Gulf of Mexico Reefs: Past, Present and Future
}

\author{
Rowan C. Martindale ${ }^{1 * \dagger}$, Daniel Holstein ${ }^{2 \dagger}$, Nancy Knowlton ${ }^{3}$, Joshua D. Voss ${ }^{4}$, \\ Anna M. Weiss ${ }^{1,5}$ and Adrienne M. S. Correa ${ }^{6 * t}$ \\ ${ }^{1}$ Department of Geological Sciences, Jackson School of Geosciences, The University of Texas at Austin, Austin, TX, \\ United States, ${ }^{2}$ Department of Oceanography and Coastal Sciences, Louisiana State University, Baton Rouge, LA, \\ United States, ${ }^{3}$ National Museum of Natural History, Smithsonian Institution, Washington, DC, United States, ${ }^{4}$ Harbor \\ Branch Oceanographic Institute, Florida Atlantic University, Fort Pierce, FL, United States, ${ }^{5}$ Kimbell School of Geosciences, \\ Midwestern State University, Wichita Falls, TX, United States, ${ }^{6}$ Departmentof BioSciences, Rice University, Houston, TX, \\ United States \\ Keywords: ecology, Gulf of Mexico, coral reef, biodiversity, disturbance, paleontology, \\ interdisciplinary/multidisciplinary
}

Editorial on the Research Topic

Gulf of Mexico Reefs: Past, Present and Future

\section{INTRODUCTION}

OPEN ACCESS

Edited and reviewed by:

Eric Jeremy Hochberg,

Bermuda Institute of Ocean Sciences,

Bermuda

*Correspondence:

Rowan C. Martindale

martindale@jsg.utexas.edu

Adrienne M. S. Correa

ac53@rice.edu

†These authors have contributed equally to this work

Specialty section:

This article was submitted to Coral Reef Research,

a section of the journal

Frontiers in Marine Science

Received: 21 May 2021

Accepted: 21 June 2021

Published: 19 July 2021

Citation:

Martindale RC, Holstein D, Knowlton N, Voss JD, Weiss AM and Correa AMS (2021) Editorial: Gulf of Mexico Reefs: Past, Present and Future. Front. Mar. Sci. 8:713058. doi: 10.3389/fmars.2021.713058
Bounded by Cuba, Mexico, and the United States, the Gulf of Mexico (GoM) contains vast, relatively understudied modern and geological reefs. GoM reef environments are extremely valuable (Natural Resources Defense Council, 2010) but experience a range of disturbance regimes (Gil-Agudelo et al.; Cummings et al., 2018). Nevertheless, some offshore reefs remain remarkably healthy (e.g., Johnston et al., 2016). The prospects for new discoveries through the study of reefs in the GoM are extensive. To foster interdisciplinary discussions and new collaborations, the "Gulf of Mexico Reefs: Past, Present and Future Symposium" was held at Rice University in Houston (TX, USA) in 2018. This symposium brought together forty scientists (Figure 1D) from various institutions, and resulted in several (new) multi-institutional collaborations (Figures 1A,B) as well as this Special Topic, which summarizes the state-of-the-field for GoM reef systems (Figure 1C) from a transdisciplinary perspective. Below, we highlight findings from 12 contributions (11 Research Articles and 1 Opinion).

\section{BIODIVERSITY AND ECOLOGY}

Many ecosystems in the GoM lack basic ecological or genomic characterization; several articles herein address this issue. Limer et al. utilized larval transport models to investigate mechanisms enhancing coral larval retention at the Flower Garden Banks on the Texas-Louisiana shelf. These reefs are thought to be relatively isolated from anthropogenic influence (but see Wright et al.; Shore et al.), as well as from larval exchange with Western Atlantic reefs. Limer et al. shows that Loop Current eddies are crucial for coral larval retention, transport between adjacent banks, and redelivery of larvae after initial advection away from natal reefs; the paper also highlights the potential for these reefs as refugia. Wetmore et al. found that fish and coral diversity in the northwestern GoM are strongly linked, with the highest fish diversity at shelf-edge locations.

The GoM also contains mesophotic beds of rhodoliths (free-living spheroids of encrusting organisms). Krayesky-Self et al. cultured Rhodosorus marinus collected from such beds in the northern GoM, and discovered endolithic unicellular red algae within biogenic rhodoliths. Their 


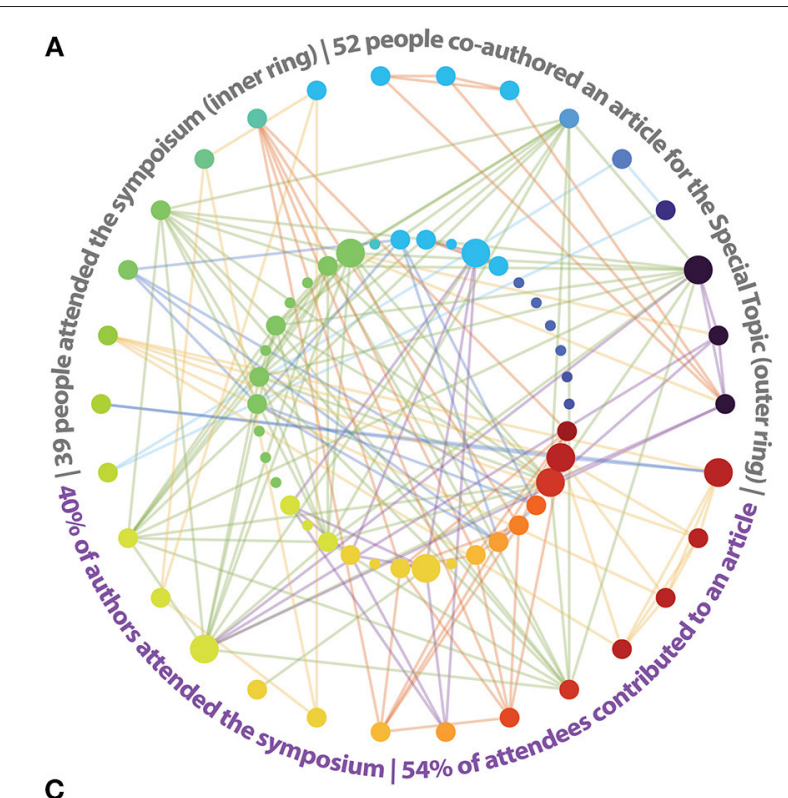

B
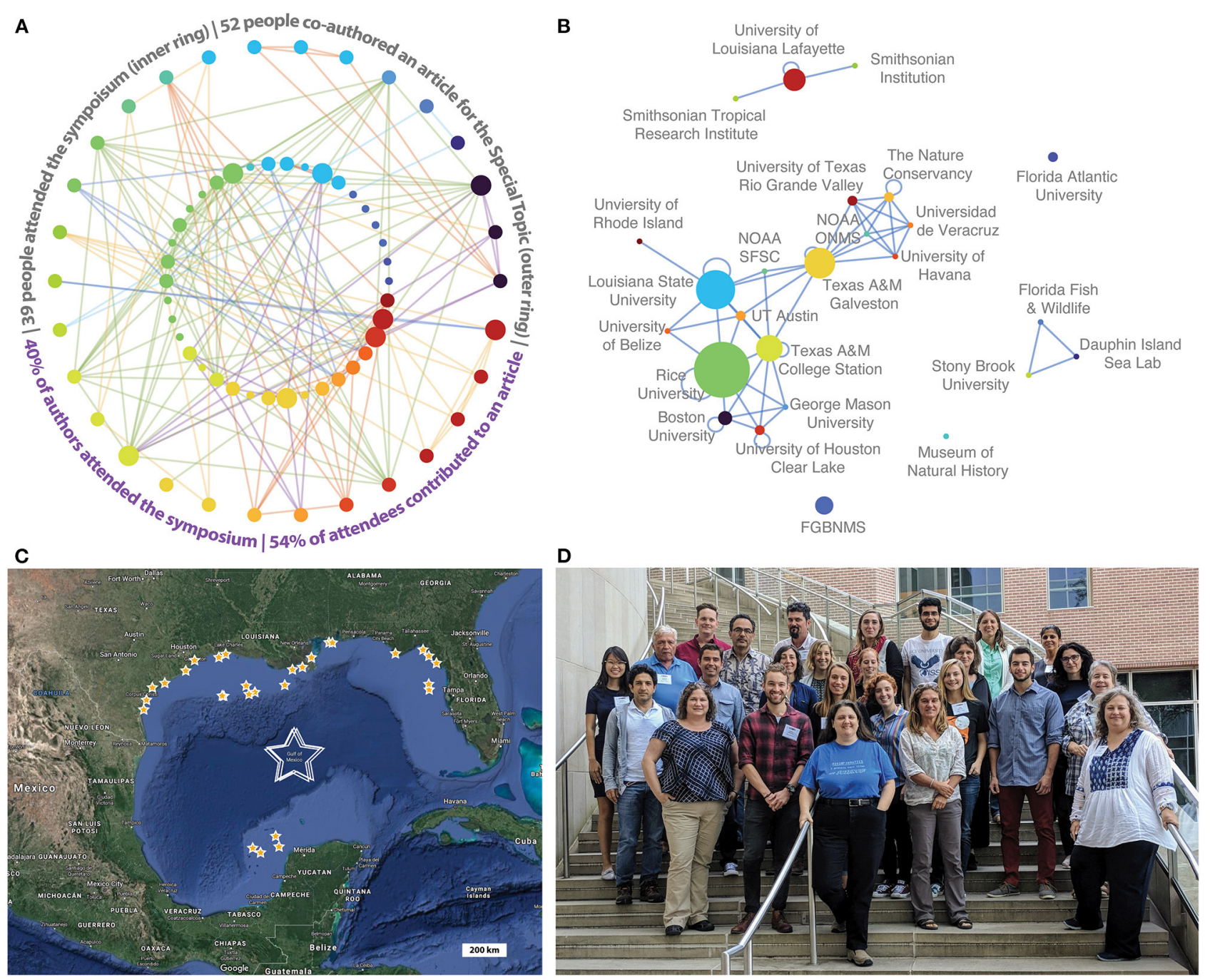

FIGURE 1 | Summary of individual and institutional collaborations in the "Gulf of Mexico (GoM) Reefs: Past, Present and Future" Special Topic. (A) Collaboration network in which nodes are individuals shaded by institutional affiliation (key in B). Node size scales with the number of papers authored in the Special Topic. Connecting lines depict paper collaborations in the Special Topic, and are shaded by manuscript. The inner circle of nodes are individuals who attended the GoM Reefs Symposium. (B) The same network, with collaborations accumulated by institution (same color scheme as A). This graph uses a force-directed layout. (C) Google Earth map depicting the Gulf of Mexico, indicating the study locations (filled stars) of papers in this Special Topic. The three open stars at the center of the GoM represent papers that span the entire gulf. (D) Subset of the participants attending the GoM Reefs Symposium held at Rice University (Houston, TX USA) on October 10-11, 2018.

results suggest rhodoliths are hotspots of biodiversity that potentially act as refugia following periods of environmental stress.

Oyster reefs act as important ecosystem engineers in GoM estuaries; La Peyre et al. summarize oyster-associated fish and decapod diversity and abundance in the northern GoM, with conservation and restoration implications. Schulze et al. discuss the community ecology of organisms that colonize fixed offshore platforms and equipment. These structures function as artificial reefs throughout a significant portion of the GoM but may also facilitate non-native invasions. This article highlights public health concerns and critical knowledge gaps related to the structure and function of these communities.

\section{ANTHROPOGENIC DISTURBANCE}

GoM reefs have experienced natural disturbances throughout geologic and modern history, with mounting recent anthropogenic pressures. As storm frequency and intensity increases due to climate change (Emanuel, 2017; Fagnant et al., 2020), understanding the associated impact on reef communities is critical. Wright et al. inferred that coastal flooding following 2017's Hurricane Harvey likely caused offshore reef organisms ( $>100 \mathrm{mi}$ from the Texas coast) to experience sub-lethal physiological stress based on gene expression changes in corals and their symbiotic dinoflagellates. Shore et al. documented that two coastal flooding events impacted these reefs based on 
shifted sponge microbiota compositions, including detections of fecal coliforms. Together, these papers indicate that offshore ecosystems are not necessarily protected from extreme coastal flooding. The Deepwater Horizon (DWH) oil spill was another major perturbation that recently impacted GoM ecosystems; Venera-Ponton et al. highlight substantial shifts in the genetic populations of a GoM-wide macroalga, Botryocladia occidentalis, following the spill. Collectively these three studies highlight the need to establish molecular and/or microbial time series and baselines for what is "typical" in GoM ecosystems. Time series data can also support the characterization and mitigation of disturbance-driven changes to the health and functioning of GoM organisms, populations, communities, and ecosystems.

\section{ECOSYSTEM FUTURES}

The current status of GoM reefs, their interconnectedness, and conservation priorities are assessed in Gil-Agudelo et al. This article also summarizes the threats reefs experience from bleaching, disease, extreme storms and invasive species. Conservation opportunities such as international sanctuary agreements, funding, and private sector support are highlighted. In a complementary Opinion article, Furman et al. predict that extensive hard bottom habitats in the Big Bend region of Florida may support the development of coral reefs in the near future. Seasonal wind patterns and simulated drifter experiments further suggest this region may be seeded by a supply of diverse coral larvae; the extent to which such larvae are presently being delivered to the Big Bend Area is a critical gap in our understanding of potential range expansion. Therefore, Furman et al. advocate for augmented eastern GoM benthic monitoring programs. Frolova and Miglietta also consider how climate change might impact the distribution of organisms in a warmer GoM. They cultured two species of Aurelia jellyfish (one a newly identified species) and found that each is tolerant of different temperature and salinity ranges.

Successful long-term conservation and monitoring strategies require accurate predictions of how environments in the GoM will change and what this means for reefs in 50-100 years. Dee et al. assess the future of GoM reef ecosystems by combining reef occurrence data with climate projections from the RCP8.5 ensemble of the Community Earth System Model v1.2. Their findings highlight the threats of prolonged, elevated temperatures and ocean acidification to GoM reef persistence. Dee et al.'s predictions are contextualized with descriptions of ancient reefs from past analogue hyperthermal climate events. The future projections show that unless long-term conservation strategies are successful and anthropogenic emissions are dramatically reduced, GoM reefs are unlikely to survive the next century of climate change.

\section{OPPORTUNITIES FOR FUTURE RESEARCH}

This Special Topic brings together disparate fields and we hope it catalyzes future international and cross-disciplinary
GoM research. Many GoM reef ecosystems require further characterization and exploration, the crucial foundation for associated conservation and restoration goals. Establishing microbial and molecular time series baseline datasets for key GoM reef-building organisms is critical for recognizing and mitigating natural and anthropogenic disturbance impacts, particularly given novel challenges to Caribbean reefs like stony coral tissue loss disease (e.g., Meiling et al., 2021). The increasing frequency and intensity of disturbances highlight the need for geographically broader and more comprehensive conservation and management strategies for GoM ecosystems. The expansion of the Flower Garden Banks National Marine Sanctuary has partially accomplished this, but without more rigorous study of ecosystem sensitivity and connectivity among the diverse reef and coastal ecosystems of the GoM, ecosystem-based management in the region remains a challenge. Finally, most contributions in this Special Topic focus on the northern Gulf of Mexico (Figure 1C), underscoring the need for greater international communication, cooperation, and collaboration among scientists across the GoM.

The 2018 Symposium highlighted the importance of bringing geologists, biologists, conservation experts, and managers together (Figure 1D). The meeting catalyzed the completion of projects and fostered new partnerships between researchers in different fields and from different institutions and countries (Figures 1A,B); many of these projects and papers would not have been initiated (or completed) without this meeting. We hope that Gulf of Mexico Reef Symposia will continue to be held regularly with broad participation from researchers spanning the gulf. Conferences such as these are particularly valuable networking opportunities for students, other early career scholars, and researchers new to the GoM region.

\section{AUTHOR CONTRIBUTIONS}

$\mathrm{AC}, \mathrm{RM}$, and $\mathrm{DH}$ wrote the manuscript and drafted the figure. All authors made a substantial, direct and intellectual contribution to the work, and have read, edited, and approved it for publication.

\section{FUNDING}

A Rice University Creative Ventures Fund and the Paleontological Society supported the 2018 Gulf of Mexico Reefs: Past, Present and Future Symposium.

\section{ACKNOWLEDGMENTS}

We thank all of the participants of the 2018 Gulf of Mexico Reefs: Past, Present and Future Symposium for their enthusiasm, engagement, and interdisciplinary collaboration. We also thank the Frontiers in Marine Science editorial staff for their support in producing this Special Issue. 


\section{REFERENCES}

Cummings, K. E., Ruzicka, R. R., Semon-Lunz, K., Brenner, J., Goodin, K. L., and Ames, K. W. (2018). "Ecological resilience indicators for coral ecosystems," in Ecological Resilience Indicators for Five Northern Gulf of Mexico Ecosystems, eds K. L. Goodin, D. Faber-Langendoen, J. Breener, S. T. Allen, R. H. Day, V. M. Congdon, C. Shepard, K. E. Cummings, C. L. Stagg, C. A. Gabler, M. Osland, K. H. Dunton, R. R. Ruzicka, K. Semon-Lunz, D. Reed, and M. Love (Arlington, VA: NatureServe), 71.

Emanuel, K. (2017). Assessing the present and future probability of Hurricane Harvey's rainfall. Proc. Natl. Acad. Sci. U.S.A. 114, 12681-12684. doi: $10.1073 /$ pnas.1716222114

Fagnant, C., Gori, A., Sebastian, A., Bedient, P. B., and Ensor, K. B. (2020). Characterizing spatiotemporal trends in extreme precipitation in Southeast Texas. Natural Hazards 104, 1597-1621. doi: 10.1007/s11069-020-04235-x

Johnston, M. A., Embesi, J. A., Eckert, R. J., Nuttall, M. F., Hickerson, E. L., and Schmahl, G. P. (2016). Persistence of coral assemblages at East and West Flower Garden Banks, Gulf of Mexico. Coral Reefs 35, 821-826. doi: $10.1007 /$ s00338-016-1452-x
Meiling, S. S., Muller, E. M., Lasseigne, D., Rossin, A., Veglia, A. J., MacKnight, N., et al. (2021). Variable species responses to experimental stony coral tissue loss disease (SCTLD) exposure. Front. Mar. Sci. 8:464. doi: $10.3389 /$ fmars.2021.670829

Natural Resources Defense Council, I. (2010). The Economic Value of the Gulf of Mexico's Ocean Resources. www.nrdc.org/sites/default/files/wat_10051101a. pdf.

Conflict of Interest: The authors declare that the research was conducted in the absence of any commercial or financial relationships that could be construed as a potential conflict of interest.

Copyright (c) 2021 Martindale, Holstein, Knowlton, Voss, Weiss and Correa. This is an open-access article distributed under the terms of the Creative Commons Attribution License (CC BY). The use, distribution or reproduction in other forums is permitted, provided the original author(s) and the copyright owner(s) are credited and that the original publication in this journal is cited, in accordance with accepted academic practice. No use, distribution or reproduction is permitted which does not comply with these terms. 